\title{
Promoting Independent Learning
}

\author{
Ofelya Poghosyan, Varduhi Ghumashyan \\ Yerevan State University
}

\begin{abstract}
At present the role of independent learning has become more crucial than ever.

The rapid development of close ties between the countries of the world, the requirement of urgent solutions to numerous problems connected with ecology, peace, politics, economy, art, etc. have strengthened the need for an international global language in order to exchange information between different cultures. Today this language is English and, consequently, learning English has become a must.

The effectiveness of learning in general and that of independent learning in particular depends on the level of responsibility of the students. In other words, the student, who in fact is a learner, should have a clear idea of the plan of his/her study. The students should know how much time, effort and money they are going to 'invest' into their studies, and, moreover, they should be responsible for their own role in the interactive, student-centered 'give and take' process of learning a foreign language.
\end{abstract}

Key words: independent learning, interactive teaching, critical thinking, studentcentered teaching, strategic investment.

\section{Introduction}

It is an undeniable fact that we (whoever we are: teachers, scholars, doctors, or just a human beings who have brains) do not develop when things are easy; we develop when we face challenges. Since challenges turn up every now and then, we have to be lifelong learners.

The new changes in all spheres of life - political, economic, cultural - make people take into account the new rules of the new games: to be flexible and be able to make transition from one frame of existence to another. Therefore, today's education more than ever requires that a learner should take bigger responsibility for his/her own learning.

\section{What does 'Independent Learning' Mean and How does it}

\section{Respond to Modern Challenges in Respect of Learning?}

The concept of Independent learning is closely interrelated with the terms frequently highlighted in modern methodological literature, namely critical thinking, creative thinking, interactive teaching, learning by doing, etc.

The essence of these concepts, however, can mean different things to different people in different disciplines and cultures. Therefore, all these terms should be 
explained to students so that they know what is required from them within the new context and discipline. Philip Candy (1991:19) quotes Foster (1972) to define independent learning/study as follows: "Independent learning is a process, a method and a philosophy of education: in which a student acquires knowledge by his/her own efforts and develops the ability for inquiry and critical evaluation."

The results of long observations and studies have brought us to the conclusion that in the learning process the learner's motto should be 'we forget what we hear, we remember what we read, we learn what we do'; in other words, we learn by doing things. It is required that independent learning should include:

a) Freedom of choice in determining the objectives within limits of a given project or program and with the aid of a faculty adviser, counsellor, guide.

b) Independent learning requires freedom of process to carry out the objectives.

c) Finally, the most important characteristic, the most crucial and essential, is that it places increased educational responsibility on the student to achieve the objectives and evaluate the goals. Thus, it can be stated that independent learning in its broadest sense is based on the so-called 'strategic investment' - a type of cognitive principle, besides automaticity, meaningful learning, the anticipation of reward and intrinsic motivation (Brown 2001). Any learner, and especially a language learner, needs a set of skills that is acquired by combining the following actions: observing, focusing, practicing, monitoring, correcting and redirecting.

\section{Strategies-Based Instruction}

Language is probably the most complex set of skills one could ever seek to acquire, therefore an investment in the form of developing multiple layers of strategies is necessary in order to get that language into one's brain.

In an era of communication, interactive, learner-centered teaching, SBI (strategiesbased instruction) simply cannot be overlooked.

Unfortunately, most teachers are so consumed with the 'delivery' of language to their students that they neglect to devote some effort to prepare the learners to the process of 'receiving' the language. The students, mostly unaware of the tricks of successful language learning, simply do whatever the teacher tells them to do, having no means to question the wisdom thereof. In an effort to fill class hours with fascinating material, teachers may overlook their mission which is to enable the learners to become independent of classroom, to become autonomous learners who develop their own pathway to success. Students' unprepared discourse becomes possible when they have necessary strategic competence to hold their own viewpoint in the 'give and take' of meaningful communication. Thus, in case of independent learning students are required to take responsibility for their learning, they have to understand that a lot of effort and time should be spent in order to achieve a certain goal. The learners should be selfdirected, make decisions about what they will focus on and how much time they will 
spend on learning both inside and outside the classroom. They should understand that they need to play a more active role in the learning process and this, in its turn, will require greater self-motivation, self-direction, creativity (employing analytical and critical thinking). They will also need organization and greater self-awareness (i.e. metacognition) of their learning needs and actions.

\section{Interactive Teaching}

It is an acknowledged fact that nearly all methods of teaching are more or less intertwined, interconnected and interdependent. Hence, let us see what aspects of interactive teaching should be highlighted in connection with independent learning. In fact, the core of interactive teaching and learning is the 'give and take' process carried out through brainstorm activities. The latter should serve as feedback for both the learners and the teachers so as to assimilate the results, effects, inferences for the further development in learning.

Let us view the following two factors of interactive method of teaching from the point of view of independent learning. The teacher's role in interactive teaching is to give the students some assignment, to get back what they have done and assimilate it. Having done this, the teacher can decide what should be best to do next. Needless to say, it is also important for a teacher to share the 'secrets' of developing and using learning and communicating strategies with the students. The teaching process should be directed to impromptu feedback so as the students should become conscious of their responsibility for successful learning. These characteristics of interactive learning as well as strategy-based instruction, in fact, coincide with those typical of independent learning.

Thus, a learner should be responsible for his/her own learning, and when performing practical tasks, he/she should use critical and creative tools which develop knowledge in learning. However, it is a must that theory and practice should always go hand in hand with one another. Therefore, in the present article marked attention is paid to the theoretical foundations of interactive learning. Douglas Brown (2001) states that the theoretical foundations of interactive learning lie in what Michael Long $(1996,1985)$ described as the interaction hypothesis of second language acquisition. As far as Stephen Krashen's $(1997,1985)$ concept of comprehensible input is concerned, Long and others point out the importance of input and output in the development of language. As learners interact with each other through oral and written discourse, their communicative abilities are enhanced. Consequently, the role of input and output, in other words, that of interactive teaching and learning, comes to be essential for independent learning as well.

In recent researches on FLT the term whole language has been widely and divergently used, but as R. Pat (1991) states in her article, today it is unfortunately on the verge of losing the impact that it once had. 
Initially the term came from reading research and was used to emphasize the following: (a) the "wholeness" of language as opposed to views that fragmented language into its bits and pieces of phonemes, graphemes, morphemes, and words; (b) the interaction and interconnection between oral language (listening and speaking ) and written language (reading and writing); and (c) the importance (in literary societies) of the written code as natural and developmental, just as the oral code is (Brown 2001).

Now the term encompasses more than that, i.e. the term whole language is used to describe cooperative learning, participatory learning, student centered learning, focus on the community of learners, focus on the social nature of language, use of authentic language, meaning-centered language, holistic assessment techniques in testing, integration of the "four skills". Nevertheless, whole language is not an activity that a teacher can employ and schedule into the lesson. It is an educational way of life that helps people to build meaningful connections between everyday learning and school learning (Edelsky 1993). In fact, two interconnected concepts are brought together in the term whole language: a) the wholeness of language implies that language is not the sum of its many discrete parts. The first language acquisition of children takes place and begins by perceiving "wholes" (sentences, emotions, intonation patterns) before "parts" (Brown 2001). In other words, second language teachers should help their students by employing such "wholes" rather than by trying to build language from bottom up. As far as wholeness of language includes the interrelationship of the four skills (listening, speaking, reading, and writing), it is essential that a teacher should attend consciously to the integration of two or more of these skills in her/his classroom.

Edelsky (1993:149) assumes that whole language is a perspective "anchored in a vision of an equitable, democratic, diverse society". Since language is used by a communicator to construct meaning as well as reality, by learning a language students come to understand a specific system of social actions that both constrain and liberate. Consequently, part of teachers' job is to empower their learners to liberate themselves from social, political, or economic forces which constrain them.

The term content-based instruction (CBI) is "the integration of content learning with language teaching aims. More specifically, it refers to the concurrent study of language and subject matter with the form and sequence of language presentation dictated by content material" (Brinton, Snow and Wesche 1989:150). When language becomes a medium of conveying relevant information, the learners display interest toward matters of intrinsic concern. In fact, language takes on its appropriate role as a vehicle for accomplishing a set of content goals and this is especially very important for LSP learners.

\section{Learner's Responsibility for His/Her Own Learning}

Over the last twenty years, the field of cognitive science has taught us a lot about how people learn. A central principle that has been generally accepted is that everything 
we learn is 'constructed' for ourselves. That is, any external agent is essentially powerless to have a direct effect on what we learn if our brain does not do it itself. The learner should have responsibility to receive information, look for connections, analyze, interpret and make sense of it, no outside force will be able to make him do so. This does not mean that the effort has to be voluntary and conscious on our parts. Our brain takes in information and operate continuously on different levels, but only some of these levels are consciously directed. But, conscious or not, it is important to realize that learning is done through one's brain, and therefore, this process is only indirectly related to the teacher and teaching. In this respect we can note that learning becomes independent. We often face situations when even the most interesting lectures result in limited learning if our students do not do the necessary work to process it. We would like to mention some reasons why students' learning, in our opinion, may fall short of expectations in classroom situations:

a) Students fail to understand a crucial concept part-way through the lecture and, as a result, what follows will be unintelligible for them.

b) Students miss some important information or do not understand well what went before, so the conceptual structures on which the lecture is built are absent in their mental framework.

c) Students lack interest or motivation, they are unwilling to make a mental effort and follow the presentation. Moreover, the desire to understand the arguments and validate the inferences is absent.

\section{Conclusion}

To sum up, it should be stated that in the process of "changing winds and shifting sands', as Albert Mackwardt (1972:5) said, about every quarter of a century a new method of learning emerges, depending on the changes in all spheres of life in general and in educational sphere in particular. Each new method breaks from the old one but takes some of the positive aspects of the previous practices with it. Independent learning is not an exception in this respect. Independent learning is an example of the cyclical nature of methods found today, another key to the solution of the problem of learning. The solution will become possible due to the learners' responsibility to collect information, look for connections, analyze, interpret and make sense of it.

\section{References:}

1. Candy, Ph. (1991) Self-Direction for Lifelong Learning. Oxford: OUP.

2. Brown, D. (2001) Teaching by Principles: an Interactive Approach to Language Pedagogy. USA: San Francisco State University. 
3. Oxford, R. (1997) Cooperative Learning, Collaborative Learning, and Interaction. Three Communicative Strands in the Language Classroom. // Modern Language Journal 81:443-56. Cambridge: CUP.

4. Long, M.H. (1988) Input in Second Language Acquisition. Rowley, MA: Newbury.

5. Krashen, S.D. (1985) The Input Hypothesis. London: Longman.

6. Rigg, P. (1991) Whole Language in TESOL. // TESOL Quarterly 25:525-42. Cambridge: CUP.

7. Edelsky, C. (1993) Whole Language in Perspective. // TESOL Quarterly 27:548-50.

8. Snow, M.A. (1998) Trends and Issues in Content-Based Instruction. //Annual Review of Applied Linguistics. New York: CUP, pp. 243-67.

\section{hGpGinınnıja nıunıgưuG jupuanıự}

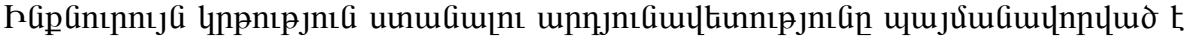

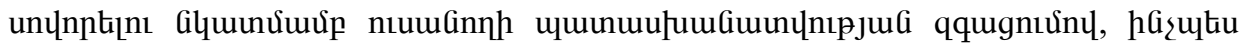

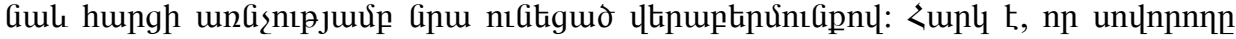

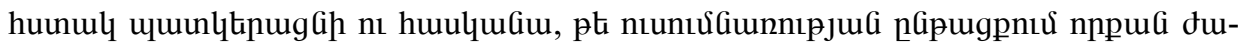

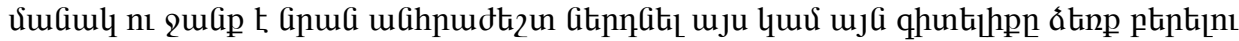
huưup:

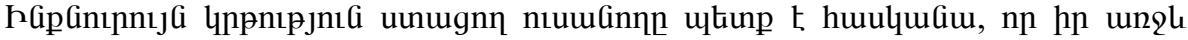

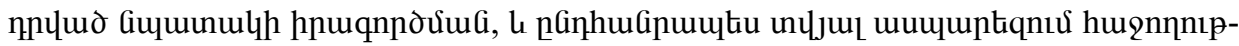

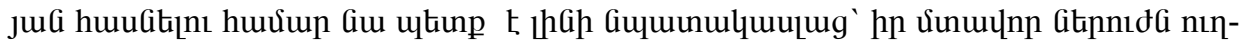

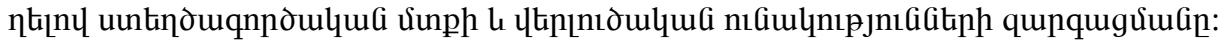

\section{Развитие самостоятельного обучения}

Эффективность самостоятельного обучения впрямую зависит от степени чувства ответственности студента к поставленной им цели получить те или иные знания в данной сфере. Студент должен ясно и четко сознавать какие усилия и какое время ему/ей потребуется для приобретения конкретных знаний и достижения конкретной цели.

Студенту важно осознать, что только благодаря собственным усилиям и целенаправленности, развивая свои креативные и аналитические способности, возможно достичь определенных успехов и поставленной цели. 